\title{
Investigating the effects of a polyester preforming binder on the mechanical and ballistic performance of E-glass fiber reinforced polyester composites
}

\author{
Metin Tanoğlu ${ }^{\mathrm{a}, *}$, A. Tuğrul Seyhan ${ }^{\mathrm{b}}$ \\ ${ }^{a}$ Mechanical Engineering Department, İzmir Institute of Technology, Gülbahce Kampüs, 35437 Urla/İzmir, Turkey \\ ${ }^{\mathrm{b}}$ Material Science and Engineering Program, İzmir Institute of Technology, Gülbahçe Kampüs, 35437 Urla/İzmir, Turkey
}

Accepted 4 September 2002

\begin{abstract}
An experimental investigation was carried out to determine the effects of a preforming binder on the mechanical properties and ballistic performance of E-glass-fiber/polyester composite systems. The glass preforms were consolidated by application of heat and pressure over plies of the glass fabrics coated with various concentrations of a thermoplastic polyester binder. The peel strength of the preforms with various binder content was measured and the highest peel strength was obtained from preforms prepared with about $9 \mathrm{wt} \%$ of the binder. Composite laminates with and without binder were fabricated using VARTM technique and the effects of the binder on the composite mechanical properties were evaluated. It was found that the flexural strength and mode I interlaminar fracture toughness decreases by $15 \%$ and $40 \%$, respectively, due to the presence of $3 \mathrm{wt} \%$ of the binder. Ballistic test was performed on E-glass/polyester composite panels using 1.1-g fragment-simulating projectiles and it was found that the binder amount has some considerable effect on the damage extension of the impacted composites. The results showed that the preforming binder has significant potential to tailor composite properties.
\end{abstract}

(C) 2003 Elsevier Science Ltd. All rights reserved.

Keywords: B. Composites; C. Destructive testing; D. Fracture; D. Impact; Glass preform

\section{Introduction}

Fiber reinforced polymer matrix composites (PMCs) have received considerable attention in recent years due to their high strength, high durability, design flexibility and light weight over traditional materials. As a result of superior performance capabilities, PMCs are used widely in marine bodies, aircraft structures and armor for ballistic protection in military applications. Composite materials are also playing a key role in the development of polymer-composite/ceramic integral armor systems that contain multiple layers of glass fiber-reinforced PMCs [1-6]. For these applications, sized glass fibers are being employed with epoxy, vinyl ester and polyester resin systems. During dynamic loading of the composite structure, a variety of damage

*Corresponding author. Tel.: +90-232-498-6597; fax: +90-232-4986505.

E-mail address: mtanoglu@likya.iyte.edu.tr (M. Tanoğlu). mechanisms including fiber/matrix interphase related micro-mechanisms such as fiber pull-out and macromechanism such as delamination at the interlaminar region may occur [5-8]. The mechanisms through which energy is absorbed during dynamic loading are critical to the ballistic or impact resistance of fiber-reinforced composites.

Resin Transfer Molding (RTM) and Vacuum-Assisted Resin Transfer Molding (VARTM) techniques are recognized to have high potential to fabricate affordable polymeric composite structures. These techniques provide higher fiber volume fraction, better surface quality and microstructural control as compared to traditional techniques such as spray up and hand lay up processes. The main processing steps in RTM or VARTM are; placement of the reinforcing fabric into a mold cavity or on a flat tool, resin infusion, curing and demolding. There are some advantages of using fabric preforms that can be prepared in the shape and dimensions of the desired part prior to resin infusion [9-12]. These include 
ease of handling and mold replacement of reinforcing constituent. Composites with higher fiber volume fraction can be obtained from compacted preforms. Also, use of preforms offer significant potential in cost savings in terms of composite manufacturing time. Furthermore, it may improve the control of dimensional specifications and fiber alignment of the final cured composite part. The most recent technique to consolidate fiber preform systems is to introduce a thermoplastic binder between reinforcement fabrics to supply brief compaction [9-13]. Thermoplastic binders offer potential to make net shape thermoformable preforms to keep integrity of fibers during mold assembly. Preforms can be fabricated by first uniformly spreading and then melting the binder onto the surface of the glass mats. The desired number of binder-coated plies can be stacked together under application of heat and pressure. In addition to chemical compatibility and reactivity of the binder with matrix resin as well as fiber sizing, physical properties of binder such as melt viscosity, wettability of the glass fabric and solubility in the applied matrix resin may significantly affect the properties of the final composite part. Dissolution of the binder may directly cause an increase in the resin viscosity. This is an important parameter on the composite processing because permeability of the resin through the binder path depends upon the degree of dissolution of binder in the matrix resin [14]. Binder properties such as modulus or the area of the binder coverage on the fibers have been found to have some considerable effects on fabricating net-shaped preforms with reduced springback [15]. It has been investigated by several studies that the presence of preforming binder has some significant effect on the mechanical and physical properties of the polymeric composites $[9,13,16]$. Furthermore, it was shown that the chemical compatibility of the binder with the matrix resin and fiber sizing is an essential for mentioned composite properties [13].

In the present work, the effects of a polyester preforming binder on the mechanical properties and ballistic performance of the E-glass fiber/polyester composite systems were investigated. The glass fiber preforms were consolidated under heat and pressure using thermoplastic polyester binder with various concentrations. Peel strength of the preforms was measured using a T-peel test method. The effect of binder on composite flexural strength and modulus, and interlaminar shear strength values were evaluated using flexural test and short beam shear (SBS) test, respectively. Mode I interlaminar fracture toughness of the composite panels was measured using double cantilever beam (DCB) test technique. To our knowledge, there is no work reported in the literature revealing the effects of a preforming binder on the ballistic performance of the composites. Ballistic testing in accordance with NATO standards was performed to evaluate the effects of the binder on the ballistic performance of composite panels with various binder concentrations.

\section{Experimental}

\subsection{Materials}

E-glass fibers and a polyester thermosetting resin (Neoxil 266) were purchased from CamElyaf Corporation of Turkey to fabricate composites. The accelerator and initiator for the resin were Cobalt Naphthenate (CoNAP) and Methyl Ethyl Ketone Peroxide (MEKP), respectively. The concentration of CoNAP and MEKP was optimized as 0.2 and $1.5 \mathrm{wt} \%$ of the resin to complete the infusion of the composite part prior to resin gelation. The preforming binder used in this work was ATLAC 363E, a bisphenol-A based thermoplastic polyester with fumerate groups in the backbone. The melting point $\left(T_{\mathrm{m}}\right)$ of the powdered binder was measured at $60^{\circ} \mathrm{C}$, from the DSC profile of the binder as shown in Fig. 1.

\subsection{Preform consolidation}

Glass preforms were consolidated from the glass fabrics by uniformly spreading of 3 and $6 \mathrm{wt} \%$ of the polyester binder onto the glass mats. The desired number of binder-coated plies were stacked together under compression pressure of $80 \mathrm{MPa}$ for about $45 \mathrm{~min}$ at a temperature of $80^{\circ} \mathrm{C}$, which is above the $T_{\mathrm{m}}$ of the binder. After completion of the preform consolidation, the preforms were allowed to cool down to room temperature under pressure. Upon re-solidification of the binder, consolidated preforms were obtained. Preforms for the peel test were prepared with 3, 6, 9 and $12 \mathrm{wt} \%$ of the binder based on the same procedure outlined above. For the peel test, only two layers of the glass fabrics $200 \mathrm{~mm}$ in length and $25 \mathrm{~mm}$ in width were bonded together and a Kapton ${ }^{\circledR}$ film was inserted in the midplane of one end of the specimen

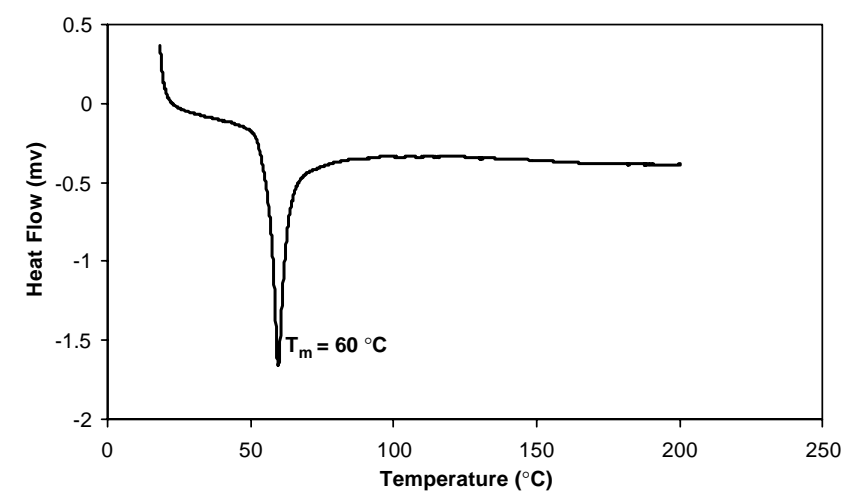

Fig. 1. DSC profile of the ATLAC 363E polyester preforming binder. 
such that an initial unbond peel length of $50 \mathrm{~mm}$ was obtained.

\subsection{Composite fabrication}

Composite laminates were manufactured using VARTM technique. In this technique, preforms were placed on a flat tool that is coated with a release agent to ease the peeling of the parts. Preforms were infused with the reacting resin under a vacuum pressure. After completion of the resin infusion and curing, the parts were demolded and transferred into an oven for postcuring at $110^{\circ} \mathrm{C}$ for $2 \mathrm{~h}$. Ballistic test panels with dimensions and areal densities (mass per unit area) shown in Table 1 were fabricated with various binder concentrations. In addition to ballistic panels, composites laminates were fabricated for SBS (10 mm thick), DCB (2.5 mm thick) and flexural test (4 mm thick). For DCB specimens, a $65 \mathrm{~mm}$ long Kapton ${ }^{\circledR}$ film was inserted in the midplane of the composites as a crack initiator for interlaminar fracture toughness testing.

\subsection{Ballistic testing}

Ballistic testing on composite panels was conducted using 1.1-g fragment-simulating projectiles (FSPs) in accordance to NATO Standard 2920. The striking velocity of the projectiles was measured using a chronograph. The specimens were examined after the test and the size of the visible impact damage was measured on the front and the back surface of the panels. Cross-section of ballistic panels were also examined under optical microscope to investigate the damage modes within the impact-affected zones.

\subsection{Mechanical property characterisation}

The peel strength (bonding strength) of the preforms was determined using a T-peel test method, ASTM D1876-95. The peel test was also used to optimize the concentration of the binder on the glass fabric. Test specimens $200 \mathrm{~mm}$ in length and $25 \mathrm{~mm}$ in width were sectioned from larger preforms. Specimens were tested

Table 1

Characteristics of VARTM processed composite panels for ballistic testing

\begin{tabular}{lllll}
\hline $\begin{array}{l}\text { Ballistic } \\
\text { panel }\end{array}$ & $\begin{array}{l}\text { Binder } \\
\text { concentration } \\
(\mathrm{wt} \%)\end{array}$ & $\begin{array}{l}\text { Area } \\
\left(\mathrm{cm}^{2}\right)\end{array}$ & Mass $(\mathrm{g})$ & $\begin{array}{l}\text { Areal density } \\
\left(\mathrm{g} / \mathrm{cm}^{2}\right)\end{array}$ \\
\hline 1 & 6 & 750.7 & 1859 & 2.47 \\
2 & 6 & 731.7 & 1851 & 2.52 \\
3 & 3 & 731.7 & 1720 & 2.35 \\
4 & 3 & 753.5 & 1766 & 2.34 \\
5 & 0 & 737.1 & 1671 & 2.26 \\
6 & 0 & 734.4 & 1667 & 2.26 \\
\hline
\end{tabular}

using an universal test machine with a constant cross speed of $5 \mathrm{~mm} / \mathrm{min}$. Average peel strength of the samples was calculated based on the average peeling load per unit width of the bond line. The flexural test technique, ASTM D 790-92 was used to determine the effects of binder on the flexural strength and modulus of the composites. For this purpose, test specimens with $25 \mathrm{~mm}$ in width and $80 \mathrm{~mm}$ in length were sectioned from the VARTM processed panels using a diamond saw. Specimens were tested in 3-point bending configuration with a span to thickness ratio of 32 . At least five specimens from composites with 3 and $6 \mathrm{wt} \%$ of binder and without binder were tested using a Shimadzu ${ }^{\mathrm{TM}}$ universal test machine at a crosshead speed of $5 \mathrm{~mm} / \mathrm{min}$. Force vs. deflection at the center of the beam was recorded. The flexural strength, $S$, values were calculated using

$S=\frac{3 P L}{2 b d^{2}}\left[1+6\left(\frac{D}{L}\right)^{2}-4\left(\frac{d}{L}\right)\left(\frac{D}{L}\right)\right]$,

where $P$ is the applied load at the deflection point, $L$ is the span length, $d$ and $b$ are thickness and the width of the specimen, respectively and $D$ is the deflection. The flexural modulus values, $E_{b}$, were calculated from

$E_{b}=\frac{L^{3} m}{4 b d^{3}}$

where $m$ is the slope of the tangent to the initial straight line portion of the load-deflection curve.

The apparent interlaminar shear strength of the composite specimens with (3 and $6 \mathrm{wt} \%$ ) and without binder were determined performing SBS test according to ASTM method D2344-84. The SBS specimens $80 \mathrm{~mm}$ in length and $10 \mathrm{~mm}$ in width were sectioned from the composite laminates. The length to thickness ratio and span to thickness ratio were kept constant at 7 and 5, respectively. The crosshead speed was remained constant at $5 \mathrm{~mm} / \mathrm{min}$. Ten specimens from each set were tested using the universal test machine and load at break was recorded. The apparent shear strength $\left(\tau_{\max }\right)$ was calculated, using

$\tau_{\max }=\frac{0.75 P_{\mathrm{B}}}{b d}$,

where $P$ is the breaking load, $b$ and $d$ are the width of the specimens and thickness of the specimen, respectively.

Mode I interlaminar fracture toughness of the composites with various binder contents $(0,3$ and $6 \mathrm{wt} \%$ ) was measured using DCB method, ASTM D5528 94a. The DCB specimens were sectioned from composite laminates with the length of $280 \mathrm{~mm}$ and width of $25 \mathrm{~mm}$. The loading hinges were bonded at the insert side of the specimens such that the initial delamination length, $a_{0}$ was about $65 \mathrm{~mm}$. The specimen were tested at crosshead speed of $1.5 \mathrm{~mm} / \mathrm{min}$. The 
crack length and crosshead displacement was measured using the universal test machine. Mode I fracture toughness, $G_{\text {Ic }}$, values were calculated based on modified beam theory using

$G_{\mathrm{Ic}}=\frac{3 P_{\mathrm{c}} \delta_{\mathrm{c}}}{2 b(a+|\Delta|)}$,

where $P_{\mathrm{c}}$ is the applied load and $\delta_{\mathrm{c}}$ is load displacement at the crack initiation. The terms $a, b$ and $\Delta$ are the delamination length, specimen width, and a correction factor determined experimentally from beam compliance and delamination length, respectively. Fracture surface of DCB specimens were observed using scanning electron microscopy (SEM) to investigate the failure modes of Mode I fracture specimens.

\section{Results and discussion}

\subsection{Peel strength of glass preforms}

Peel strength between glass plies was evaluated to determine the adhesion mechanisms between the glass fabric and the binder. For this purpose, 3, 6, 9 and $12 \mathrm{wt} \%$ of binder content was used to bond two E-glass plies together. Fig. 2 shows the average peel strength of the specimens as a function of binder concentration. As seen in the figure, there is a linear increase with binder content and the highest peel resistance was obtained from preforms with about $9 \mathrm{wt} \%$ of the binder. The linear increase of the peel strength is due to the improved adhesion by increased surface coverage of the fabric by the binder. At about $9 \mathrm{wt} \%$, the binder covers almost full surface and the further increase in the amount of the binder does not affect the preform peel strength.

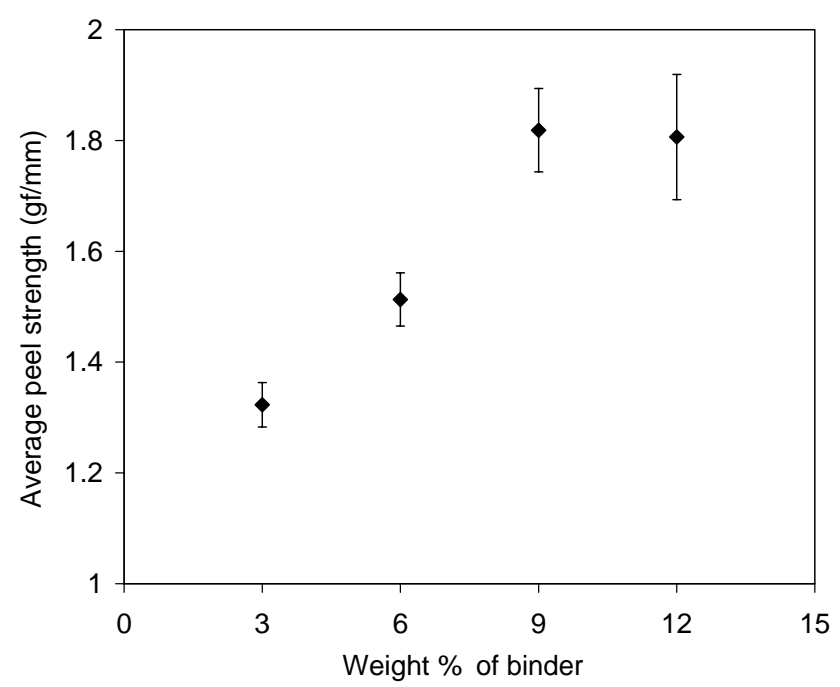

Fig. 2. Average peel strength of the specimens as a function of binder weight percentage.

\subsection{Effects of the binder on the ballistic performance of the composite}

The composite panels were subjected to ballistic impact at projectile velocities listed in Table 2. Fig. 3 is the photographs showing front and back surface of the ballistic panels with $3 \mathrm{wt} \%$ and without binder. The mode of the impact damages seen in Fig. 3 is typical for all tested panels and all of the composite targets stopped the projectiles with only partial penetration without perforation. The energy level impacted to the targets caused sufficient damage to the laminate without completely penetrating the target. This allowed us to make a comparison among the ballisticaly-impacted panels based on extent of damage given at relatively equivalent input energies. In this way, the effects of material variations such as binder concentration along the interlaminar region, on the impact response were assessed. The size of the damage and the percentage of delamination areas on the front and back surface of the panels were measured as given in Table 2. Less damage is observed at the front where projectile entered, as compared to the back surface. The damage modes within the panels were observed conducting optical microscopy on the cross-sections of impact-damaged zones. Observations revealed that microscopic (fiber fracture, etc.) and macroscopic (delamination, matrix cracking, etc.) damage mechanisms could occur in composites due to ballistic impact. Delamination type damage is visible and the delaminated area through the thickness increases, forming a conical damage zone. Fig. 4a illustrates the delamination and intra-bundle cracking type failure modes occurred within the impactdamaged zone. Interfacial debonding of the fibers and the matrix caused by intra-bundle cracking within the tows is also apparent. A cavity at the projectile contact region was formed due to the penetration. Around cavity region, significant amount of fiber and matrix failure besides folding and buckling of fibers is apparent as illustrated in Fig. 4b. The results also show that as the concentration of the binder increases in the composites, a relatively less damage, i.e. less delamination, was occurred within the back zones of the composites while no significant change was observed on the front zones. This may indicate a relatively higher energy absorbing capability of the composites with preforming binder material due to tailored properties.

\subsection{Effects of the binder on the mechanical properties of the composites}

The flexural strength and modulus values of the E-glass/polyester composites as a function of binder weight percentage are shown in Fig. 5. The results show that the presence of the polyester binder along the interlaminar region affects the flexural properties of the 
Table 2

Ballistic delamination data for the composite panels with various concentration of preforming binder

\begin{tabular}{lllllll}
\hline Panel & Binder conc. (wt\%) & Velocity $(\mathrm{m} / \mathrm{s})$ & $\begin{array}{l}\text { Front damage } \\
\text { diameter }(\mathrm{cm})\end{array}$ & $\begin{array}{l}\text { Back damage } \\
\text { diameter }(\mathrm{cm})\end{array}$ & $\begin{array}{l}\text { Delamination \% } \\
\text { (front face) }\end{array}$ & $\begin{array}{l}\text { Delamination \% } \\
\text { (back face) }\end{array}$ \\
\hline 1 & 6 & 614 & 4.25 & 7.5 & 1.88 & 5.88 \\
2 & 6 & 578 & 3.5 & 5.5 & 1.31 & 3.24 \\
3 & 3 & 609 & 4.25 & 8 & 1.93 & 6.86 \\
4 & 3 & 579 & 4 & 6.75 & 2.66 & 8.74 \\
5 & 0 & 585 & 4.5 & 8 & 1.71 & 6.62 \\
6 & 0 & 575 & 4 & 8 & & 6.84 \\
\hline
\end{tabular}

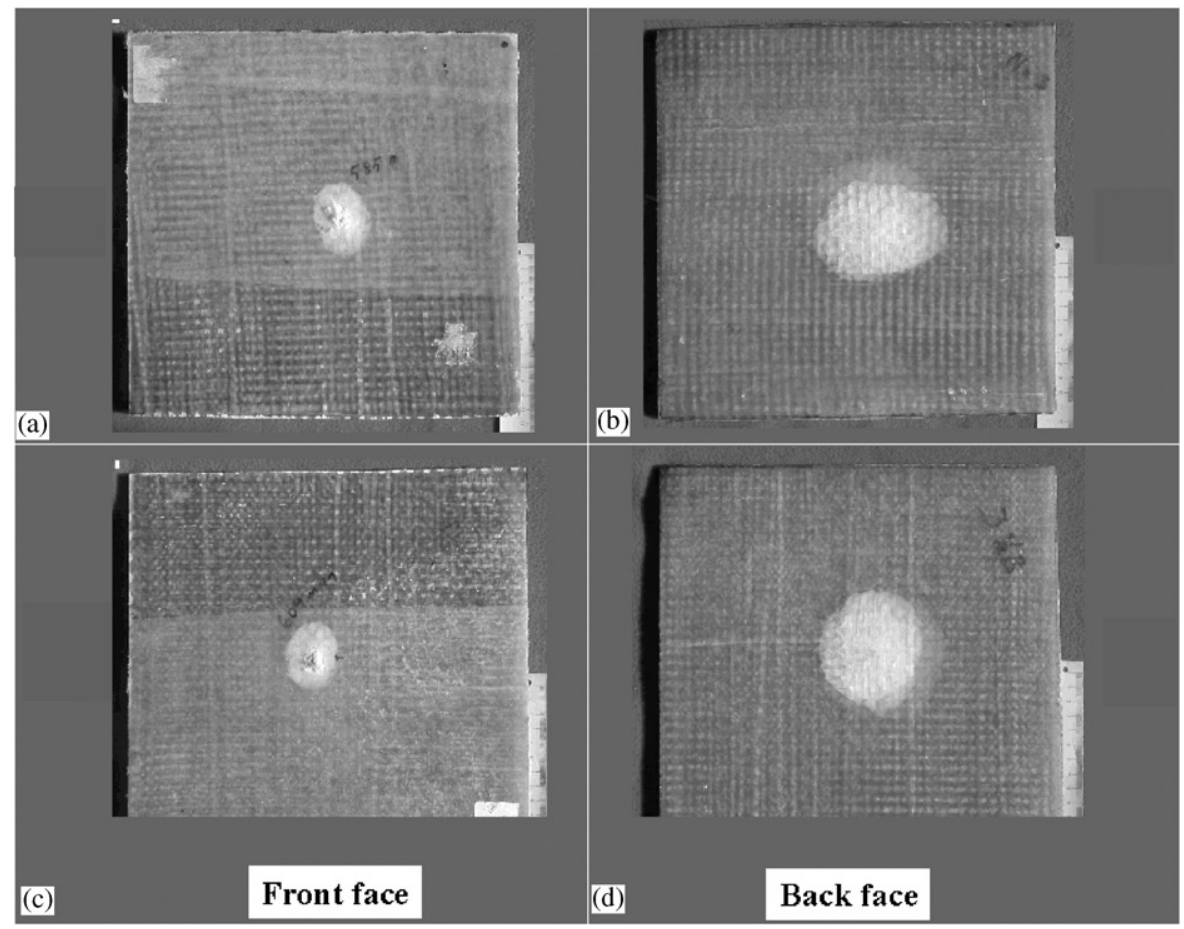

Fig. 3. Ballistic impact damage on front and back face of VARTM processed composite panels. (a and b-panels without binder), (c and d-panels with $3 \mathrm{wt} \%$ binder).

composites. The flexural strength is reduced about $20 \%$ due to the presence of $6 \mathrm{wt} \%$ of the binder. On the other hand, the modulus values are increased about $40 \%$ due to the same amount of the binder material. Fig. 6 shows the apparent average interlaminar shear strength versus binder weight percentage values. The results indicate that presence of the binder has no significant effect on the interlaminar shear strength of E-glass/polyester system.

Mode I interlaminar fracture toughness of the composite specimens with (3 and $6 \mathrm{wt} \%$ ) and without binder was measured using DCB specimens. Fig. 7 shows the $G_{\text {Ic }}$ values as a function of delamination crack extension $(\Delta a)$. It was found that composites with binder and without binder exhibit rising delamination curve behavior. The average $G_{\text {Ic }}$ values increase with crack extension and reach a constant propagation value. The average propagation values are 720,432 and $235 \mathrm{~J} / \mathrm{m}^{2}$ for 0,3 and $6 \mathrm{wt} \%$ of the binder, respectively.
The results reveal that the fracture toughness of the composites is reduced about $67 \%$ due to the presence of the $6 \mathrm{wt} \%$ polyester binder. The chemical compatibility of the sizing on the fibers with the polyester resin is a critical issue on the mechanical properties of the composites. In the present study, glass fibers used are compatible with the matrix resin system and the polyester binder does not react with the polyester matrix resin and the sizing of the fiber. Therefore, the binder acts as a barrier between the fiber sizing and the matrix resin and the chemical bonding between the fiber and the matrix resin is inhibited as the binder content increases. So, the decrease of the flexural strength and $G_{\text {Ic }}$ values with the presence of the binder may be associated with the reduced bonding between the fiber and matrix.

The effect of the fiber's sizing compatibility with the resin was studied in the previous work $[9,13]$. It was reported that the use of $3 \mathrm{wt} \%$ of the polyester binder in 

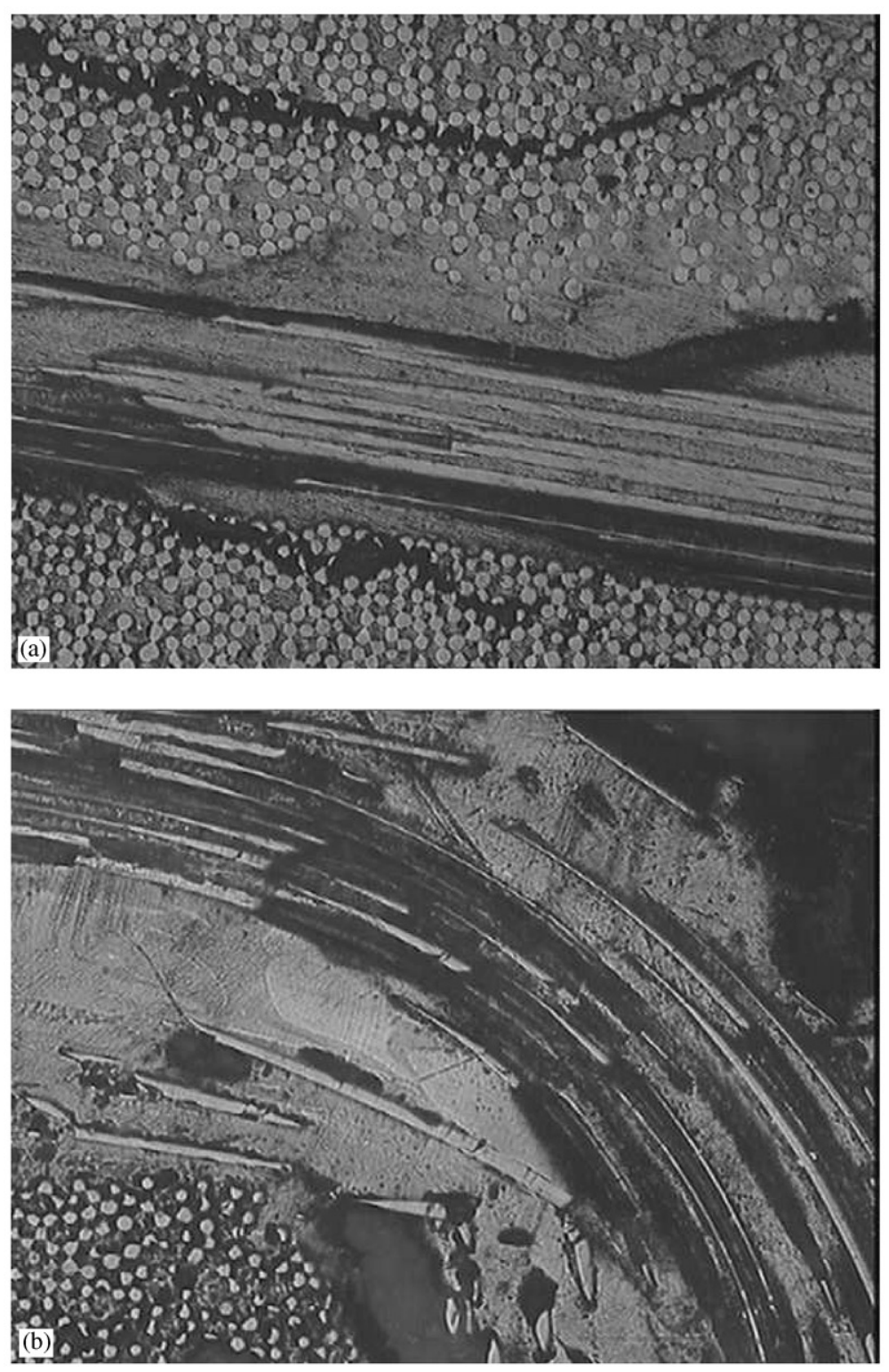

Fig. 4. (a) Optical micrographs from the cross-section of E-glass/polyester composite panel (with $3 \mathrm{wt} \%$ of the binder) after ballistic impact showing delamination and intra-bundle cracking. (b) Optical micrographs from the cross-section of E-glass/polyester composite panel (with $3 \mathrm{wt} \%$ of the binder) after ballistic impact showing fiber buckling/folding near the projectile cavity region.

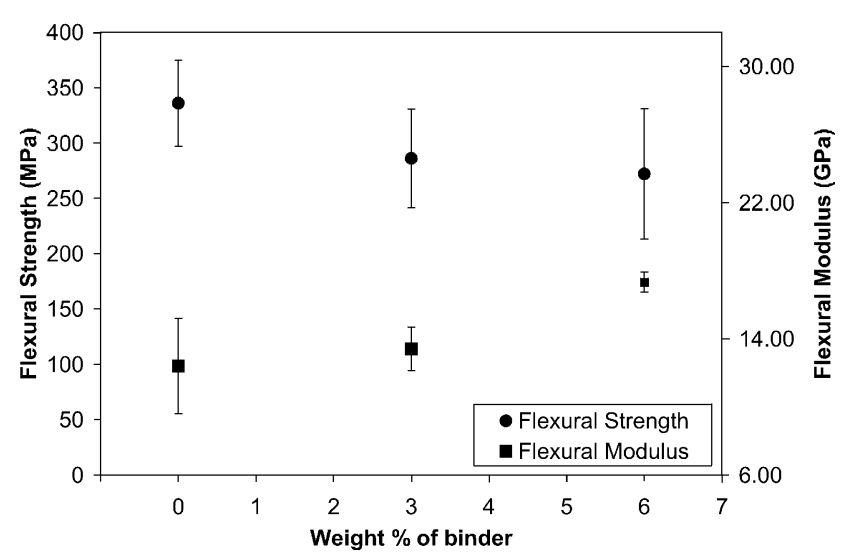

Fig. 5. Flexural strength and modulus of the E-glass/polyester composites as a function of binder weight percentage.
S2-glass/SC-15 epoxy-amine system that is made of epoxy-amine compatible sizing lowers the $G_{\text {Ic }}$ values by $61 \%$. On the other hand, it was found that for the S2glass/vinyl-ester systems that is made of vinyl ester incompatible sizing, the reduction of $G_{\text {Ic }}$ values were only limited to about $10 \%$ due to the presence of the $3 \mathrm{wt} \%$ of polyester binder. In the present study, use of $3 \mathrm{wt} \%$ of polyester binder reduces the $G_{\text {Ic }}$ values of the E-glass/ polyester composites made of polyester compatible sizing by $40 \%$. These results clearly demonstrate the interactions between the fiber sizing and matrix resin, and also the effect of the non-reactive binder on the adhesion within the composites.

Furthermore, fracture surface morphologies of the DCB specimens were examined using SEM to evaluate 


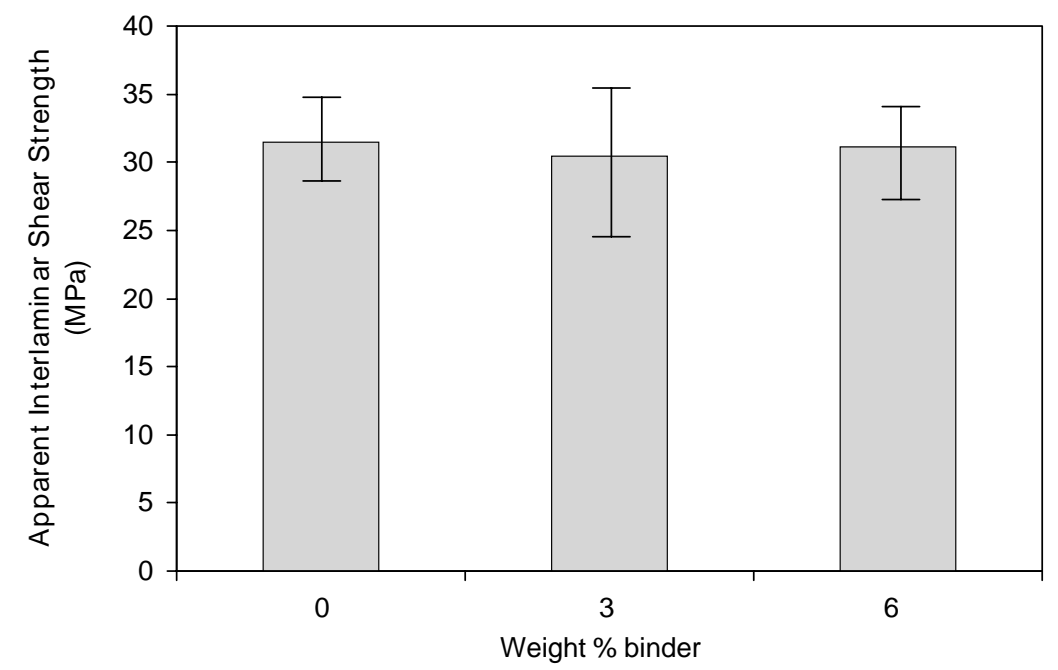

Fig. 6. Apparent interlaminar shear strength of the composites as a function of binder weight percentage.

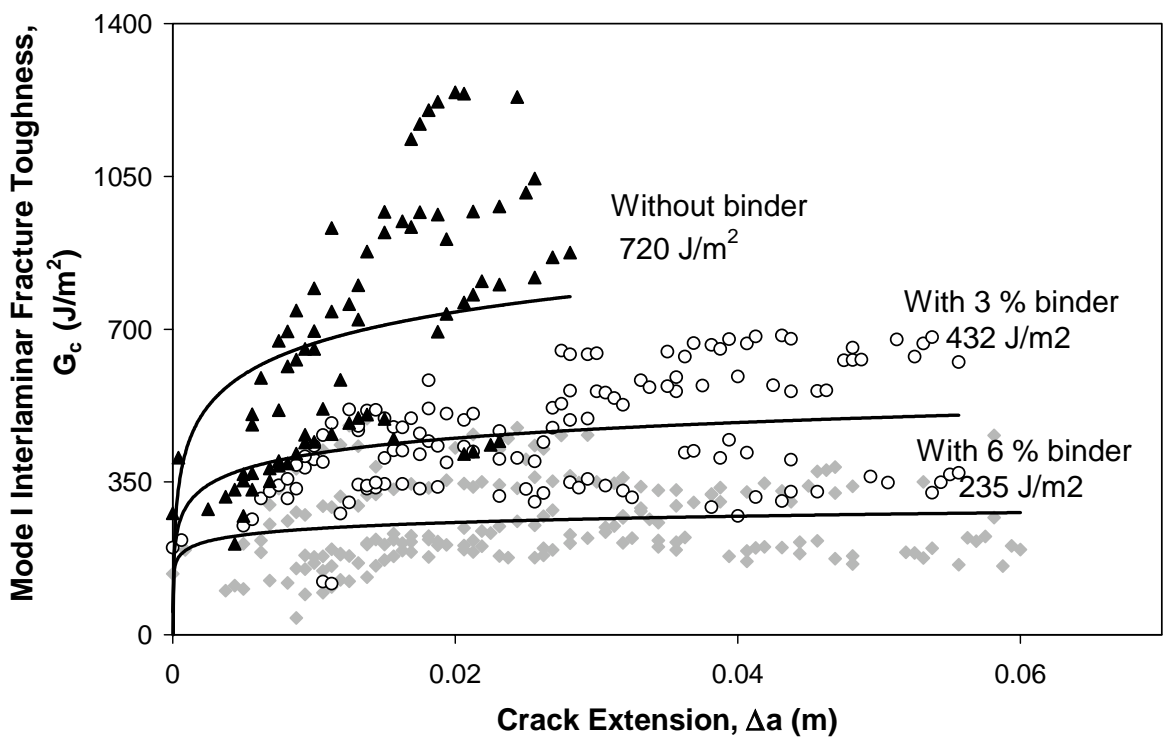

Fig. 7. Mode I interlaminar fracture toughness of E-glass/polyester composite system as a function of crack extension.

the failure mechanisms at the interlaminar region. The results show some considerable differences in the morphology of the mode I fracture surfaces for composites with and without binder. As presented in Fig. 8a and b, composite with binder exhibit great amount of interfacial failure in which the fibers are stripped of matrix material easily. This may also indicate hindered bonding between sized fiber and matrix resin due to coverage of the fiber surfaces by the binder. However, the composites without binder show some considerable amount of matrix failure besides interfacial failure and some fiber pull-out. Because of the better adhesion between the fiber and matrix, matrix deformation is also dominant rather than interfacial failure.

\section{Conclusion}

The effects of the preforming binder on the mechanical properties and ballistic performance of the E-glass/ polyester composite systems were investigated. The results showed that the powdered thermoplastics have high potential to produce thermoformable glass fabric preforms. It was found that approximately $9 \mathrm{wt} \%$ of the binder provides full coverage of the glass fabric surface. The highest peel strength was measured from the preform that has almost full binder coverage on the fabric. The further increase on the binder concentration has no significant effect on the peel strength values. Flexural strength and modulus, and interlaminar fracture toughness of the composites have gone under 

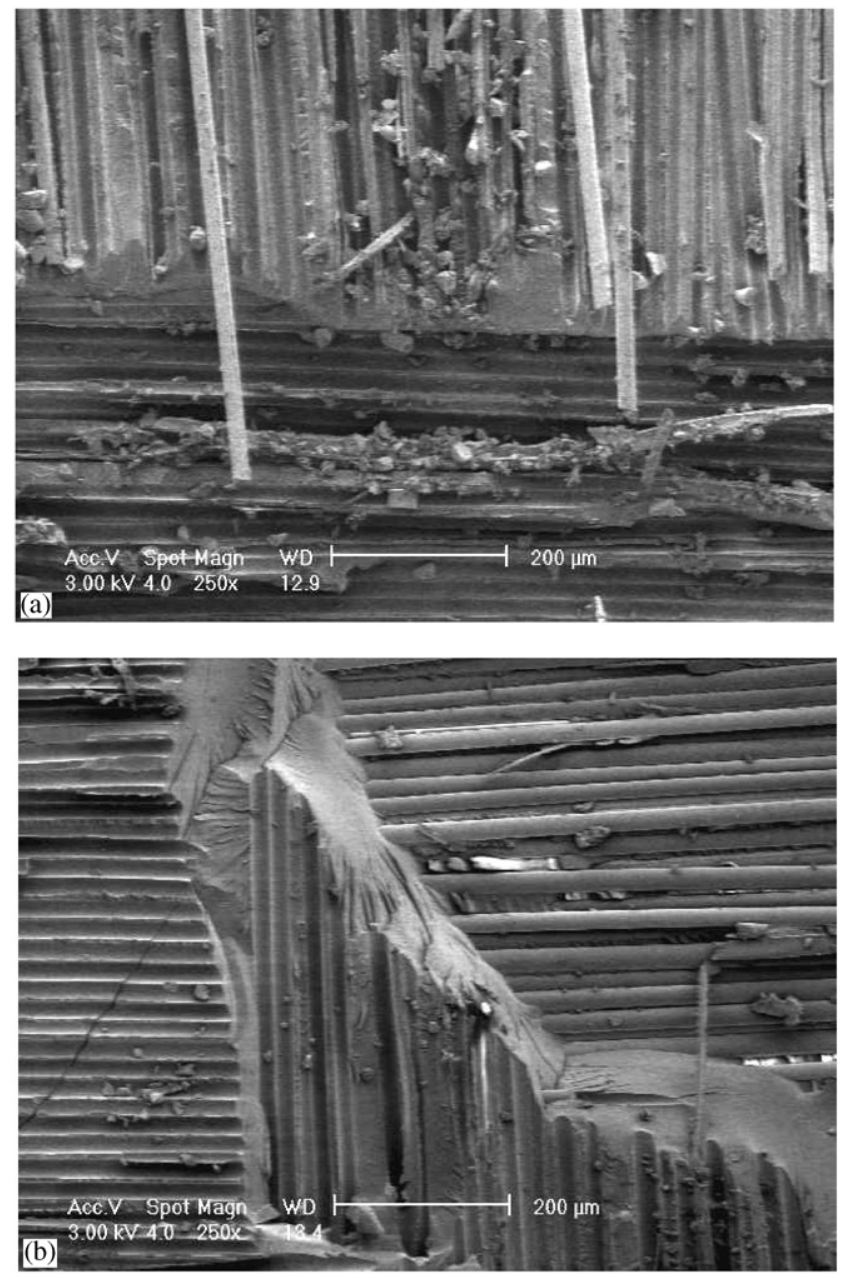

Fig. 8. (a) SEM fracture surface micrographs of DCB specimen with $0 \mathrm{wt} \%$ of binder, (b) SEM fracture surface micrographs of DCB specimen with $3 \mathrm{wt} \%$ of binder.

considerable changes by the introduction of the preforming binder. Flexural strength is decreased while flexural modulus is increased with increasing binder content. Mode I interlaminar fracture toughness of the composite laminates is significantly affected by the thermoplastic binder, i.e., $40 \%$ reduction by the presence of $3 \mathrm{wt} \%$ binder. It was found that interlaminar shear strength is not significantly affected by the presence of the binder. The results of the ballistic test showed that failure damage due to the ballistic impact is also considerably affected by the presence of the binder. The extend of the delamination type damage was observed to change due to the preforming binder. The results indicate the potential of the preforming binder to modify the properties at interlaminar region and to tailor the mechanical and ballistic performance of the polymeric composites.

\section{Acknowledgements}

The authors acknowledge the financial support from İzmir Institute of Technology under contract ArFon 2001 Müh 21. The authors wish to thank Mr. Can Candan for his assistance.

\section{References}

[1] Vaidya UK, Abraham A, Bhide S. Affordable processing of thick section and integral multi-functional composites. Composites: Part A 2001;32:1133-42.

[2] Bhatnagar A, Lin LC, Lang DC, Chang HW. Comparison of ballistic performance of composites. Proceedings of International SAMPE Symposium, Atlantic City, NJ, USA, 1989. p. 1529-37.

[3] Milton FA. Army after next proposal for ground combat vehicles. Army Science Conference, Norfolk, VA, June 1998.

[4] Smith Jr WN. Light weight armor. US Patent \# 4,732,803, 1988.

[5] Tanoğlu M, McKnight SH, Palmese GR, Gillespie Jr. JW. The effects of glass fiber sizings on the strength and energy absorption of the fiber/matrix interphase under high loading rates. Compos Sci Technol 2001;61:205-20.

[6] Bernetich KR, Fink BK, Gillespie Jr JW. Ballistic testing of affordable composite armor. Proceedings of American Society for Composites, Baltimore, MD, September 1998.

[7] Li RKY, Choy CL, Duan Z, Zhang M. An investigation of the dynamic response of continuous fiber reinforced composite laminates-failure morphology. Polym Polym Compos 1994;2(6): 355-66.

[8] Cantwell WJ, Morton J. The impact resistance of composite materials - a review. Composites 1991;22:347-62.

[9] Tanoğlu M, Robert S, Heider D, McKnight SH, Gillespie Jr. JW. Effects of thermoplastic preforming binder on properties of S2glass fabric reinforced epoxy composites. Int $\mathbf{J}$ Adhes Adhes 2001;21:187-95.

[10] Knight JC, Backes D, Jayaraman K. Consolidation and relaxation behaviour of continuous strand random glass mats with thermoplastic binder. Polym Compos 1996;17(3):451-7.

[11] Hillermeier RW, Haye BS, Seferis JC. Tackifier/binder toughened resin transfer molding composites. J Adv Mater 1999;31(4):52-9.

[12] Shih CH, Liu Q, Lee LJ. Proceedings of the 45th International SAMPE Symposium, Long Beach, CA, USA, May 2000. p. $776-87$

[13] Ziaee S, Brody JC, Tanoğlu M, Gillespie Jr JW, McKnight SH. Effects of a polyester preforming binder on properties of E-glass fabric reinforced vinyl-ester composites. Conference Proceedings of 16th Annual Technical Conference of American Composite Society, Blacksburg, VA, 10-12 September 2001.

[14] Rohatgi V, Lee LJ. Moldability of tackified fiber preforms in liquid composite molding. J Compos Mater 1997;31(7):720-44.

[15] Chen J, Backes D, Jayaraman K. Dynamics of binder displacement in liquid molding. Polym Compos 1996;17(1):23-33.

[16] Hillermeier RW, Seferis JC. Interlayer toughening of resin transfer molding composites. Composites: Part A 2001;32:721-9. 